\title{
Oxidation of Methane to Methanol over Pd@Pt Nanoparticles under Mild Conditions in Water
}

Received 00th January 20xx, Accepted 00th January 20xx

DOI: $10.1039 / \times 0 \times x 00000 x$

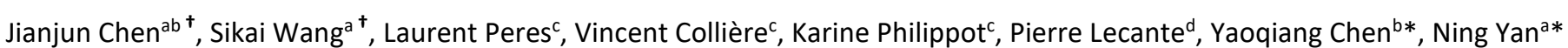

\section{Abstract:}

Direct methane oxidation into oxygen-containing chemicals under mild conditions sparks increasing interest. Here, we report Pd@Pt core-shell nanoparticles that efficiently catalyse the direct oxidation of $\mathrm{CH}_{4}$ to $\mathrm{CH}_{3} \mathrm{OH}$ in water using $\mathrm{H}_{2} \mathrm{O}_{2}$ as an oxidant under mild conditions. The catalyst presents a methanol productivity up to $89.3 \mathrm{mmol} g$ metal ${ }^{-1} \mathrm{~h}^{-1}$ with a high selectivity of $92.4 \%$ after $30 \mathrm{~min}$ at $50^{\circ} \mathrm{C}$, thus outperforming most of previously reported catalysts. Electron-enriched Pt species in the Pd@Pt nanoparticles were identified by structural and electronic analysis. Pd in the core donates electrons to Pt, leading to higher rates of methane activation. Based on the results of control experiments and kinetic analysis, a consecutive oxidation pathway via a radical mechanism is proposed, which includes initial formation of $\mathrm{CH}_{3} \mathrm{OOH}$ and $\mathrm{CH}_{3} \mathrm{OH}$ followed by further oxidation of $\mathrm{CH}_{3} \mathrm{OH}$ to $\mathrm{HCHO}, \mathrm{HCOOH}$, and $\mathrm{CO}_{2}$.

\section{Introduction}

Natural gas is receiving high attention as a valuable source of energy and chemicals. ${ }^{1,2}$ As the main component of natural gas, methane is extensively applied as a fuel and also processed into chemicals. ${ }^{3-5}$ To date, large-scale conversion of methane to liquid hydrocarbons in industry has been carried out through an indirect methane-steam reforming coupled with Fischer-Tropsch synthesis. ${ }^{6-}$ ${ }^{10}$ These steps normally involve harsh conditions with high temperature $\left(>400^{\circ} \mathrm{C}\right)$ and pressure $(>10$ bar), resulting in increased costs of operation and maintenance. ${ }^{11-15}$ Direct conversion of methane into value-added liquid fuels and chemicals such as methanol, olefins, hydrogen, and aromatics has thus become an important research topic attracting interests from both industry and academia. ${ }^{16-18}$

The direct conversion pathways include methane pyrolysis ${ }^{19}$, oxidative coupling ${ }^{20,21}$, and partial oxidation ${ }^{22,23}$. Among these, oxidation pathways are exothermic and low-temperature favoured. For instance, direct oxidation of methane into methanol $\left(\mathrm{CH}_{4}+0.5 \mathrm{O}_{2} \rightarrow 3 \mathrm{CH}_{3} \mathrm{OH}\right)$ has $\Delta H^{0}{ }_{298 \mathrm{~K}}$ value of $126.4 \mathrm{~kJ} / \mathrm{mol}$. Over a range of oxidants, such as $\mathrm{O}_{2}, \mathrm{H}_{2} \mathrm{O}_{2}$, and $\mathrm{N}_{2} \mathrm{O}$, partial oxidation has been proven viable below $200{ }^{\circ} \mathrm{C}$. Compare to the indirect syngas process, it is simpler and potentially more

Sicher and Biomolecular Engineeing, National University of Singapore, 4 Engineering Drive, Singapore 117585, Singapore, E-mail: ning.yan@nus.edu.sg

Address here. Institute of New Energy and Low-carbon Technology, Sichuan University, Chengdu 610064, China, E-mail: chenyaogiang@scu.edu.c

CNRS, LCC (Laboratoire de Chimie de Coordination), 205 route de Narbonne,

BP44099, F-31077 Toulouse Cedex 4, France.

Matériaux et d'Études Structurales), 29

Rue Jeanne-Manig 4347, F-31055 Toulouse Cedex 4, France.

the

DO1: $10.1039 / \times 0 \times x 00000 \times$ effective, but there are two main issues to overcome. First, the $\mathrm{C}-\mathrm{H}$ bond in methane is difficult to activate due to the high ionization energy, high bond energy, low polarity, as well as low electron and proton affinity of methane. ${ }^{24-26}$ Second, it is thermodynamically difficult to keep the formed methanol because the dissociation energy of $\mathrm{C}-\mathrm{H}$ bond in methanol $(392 \mathrm{~kJ} / \mathrm{mol})$ is lower than that in methane $(439 \mathrm{~kJ} / \mathrm{mol})$. Under typical reaction conditions, methanol is thus easily oxidized to $\mathrm{CO}_{2} \cdot{ }^{6}$, 27-29

Results from decades of research showed that certain homogeneous and heterogeneous catalysts are active for the selective oxidation of methane into $\mathrm{C} 1$ oxygenates under low temperatures. ${ }^{30}$ For instance, molecular complexes of $\mathrm{Pd}, \mathrm{Rh}, \mathrm{Au}, \mathrm{Hg}, \mathrm{Ru}$, and $\mathrm{Pt}$ directly oxidized methane into methanol26,31,32, but toxic/corrosive reagents such as hydrobromic acid, trifluoroacetic acid, oleum, or hydrochloric acid were heavily used. In heterogeneous catalysis, zeolite-stabilized Fe and $\mathrm{Cu}$ species are known to convert $\mathrm{CH}_{4}$ into methanol via a stepwise, separated reaction steps. ${ }^{33-39}$ In a single-step manner ${ }^{40-46}$, a few systems have been identified to be effective as well. For instance, iron atoms confined in graphene showed high selectivity $(94 \%)$ of $\mathrm{C} 1$ products $\left(\mathrm{CH}_{3} \mathrm{OOH}, \mathrm{CH}_{3} \mathrm{OH}\right.$, $\mathrm{HOCH} \mathrm{H}_{2} \mathrm{OOH}$ and $\mathrm{HCOOH}$ ) at $25{ }^{\circ} \mathrm{C}$ using $\mathrm{H}_{2} \mathrm{O}_{2}$ as an oxidant. ${ }^{47} \mathrm{TiO}_{2}$ nanoparticles supported $\mathrm{Cr}$ catalysts achieved similar selectivity at $50{ }^{\circ} \mathrm{C} .{ }^{48}$ Concerning noble metal-containing catalysts, many progresses have been acquired with Au-Pd colloid-based catalysts. ${ }^{49-51}$ Hutchings et al. ${ }^{52}$ reported high selectivity (92\%) and methanol productivity (53.6 mol $\mathrm{Kg}_{\left.\mathrm{AuPd}^{-1} \mathrm{~h}^{-1}\right)}$ over Au-Pd nanoparticles using $\mathrm{H}_{2} \mathrm{O}_{2}$ as an oxidant. Very recently, Xiao et al. ${ }^{53}$ prepared hydrophobic ZSM-5 as a molecularfence for in situ $\mathrm{H}_{2} \mathrm{O}_{2}$ generation that led to the selective oxidation of methane to methanol. This fence permitted the diffusion of the hydrophobic species like methane, oxygen, hydrogen, to PdAu active sites over the colloidal catalyst, while locally concentrating the formed $\mathrm{H}_{2} \mathrm{O}_{2}$ that allowed its rapid interaction with methane. 
Beyond $\mathrm{Au}$, heterogeneous noble metal catalysts for oxidizing methane to methanol and other oxygenates are currently not common. The $\mathrm{CH}_{3}$ intermediate is a key precursor for methanol formation in direct oxidation of methane. ${ }^{22,40,54}$ Based on DFT calculation, platinum clusters with high proportion of highly coordinatively unsaturated sites are predicted to effectively stabilize the $\mathrm{CH}_{3}$ intermediate by hindering its successive dehydrogenation. ${ }^{55-57}$ Design Pt-based colloids by incorporating a second metal to change geometric and electronic structures may be a viable approach to identify suitable catalysts to convert methane to $\mathrm{C} 1$ oxygenates.

Motivated by these analyses, in this work, a core-shell Pd@Pt catalyst dispersed in water was developed. Its structural characteristics were investigated by TEM, WAXS, CO-DRIFTS, and XPS. This catalyst was evaluated in the direct oxidation of $\mathrm{CH}_{4}$ to $\mathrm{CH}_{3} \mathrm{OH}$ using $\mathrm{H}_{2} \mathrm{O}_{2}$ as an oxidant at mild reaction conditions. The catalytic performance was correlated to the structure of the Pd@Pt coreshell nanoparticles, while the reaction pathway was established on the basis of control experiments and reaction kinetic analysis.

\section{Experimental methods}

\subsection{Catalyst Synthesis}

Monometallic Pt, monometallic Pd, and bimetallic $\mathrm{Pt}_{\mathrm{x}} \mathrm{Pd}_{\mathrm{y}}$ nanoparticles (NPs) were synthesized by a wet chemistry method using water as a solvent to provide the colloidal catalyst. The studied $\mathrm{x} / \mathrm{y}$ ratios were of $8 / 1,4 / 1,2 / 1,1 / 1,1 / 2,1 / 4$ and $1 / 8$, respectively. Typically, the procedure for the preparation for $\mathrm{Pt}_{1} \mathrm{Pd}_{1}$ colloid was as follows: an acidic solution of $\mathrm{PdCl}_{2}$ precursor and an aqueous solution of $\mathrm{K}_{2} \mathrm{PtCl}_{4}$ precursor were dissolved in de-ionized water $(500 \mathrm{~mL})$ at a total metal concentration of $0.256 \mathrm{mmol} / \mathrm{L}$. Polyvinylpyrrolidone (PVP; MW 40,000) was used as a stabilizer and added to the solution at a metal-to-PVP ratio of 1:1.2. After vigorously stirring for 30 min, freshly prepared $\mathrm{NaBH}_{4}(0.1 \mathrm{M})$ aqueous solution was slowly added to the metal precursors/PVP mixture at room temperature (r.t.) and at a metal-to- $\mathrm{NaBH}_{4}$ ratio of 1:5. The solution colour quickly changed to deep dark. The stirring was maintained for $1 \mathrm{~h}$. For the coreshell systems, namely Pd@Pt NPs and Pt@Pd NPs, Pd (or Pt) NPs were firstly prepared by $\mathrm{NaBH}_{4}$ reduction of the same metal precursors at r.t. Then Pt (or Pd) precursor was reduced in a second step at a lower temperature $\left(\sim 0^{\circ} \mathrm{C}\right)$. The second step was conducted at a lower temperature to slow down the reduction of the second metal precursor, to favor its reduction at the surface of pre-formed NPs.

\subsection{Catalytic Performance Testing and Product Analysis}

The catalytic performance testing for direct methane oxidation was performed in a stainlesssteel autoclave reactor $(30 \mathrm{~mL})$. The reactor was charged with a $\mathrm{H}_{2} \mathrm{O}_{2}$ aqueous solution $(400$ $\mu \mathrm{mol}, 1 \mathrm{M}, 0.4 \mathrm{~mL}$ ) and $2 \mathrm{~mL}$ of each colloidal solution ( $1 \mu \mathrm{mol}$ metal). After sealing, the reactor was purged with $95 \% \mathrm{CH}_{4}-5 \% \mathrm{~N}_{2}(3 \mathrm{MPa}$ ) three times to remove residual air. Then, the autoclave was re-pressurized to $3 \mathrm{MPa}$ and heated to the desired temperature at a rate of $2{ }^{\circ} \mathrm{C} / \mathrm{min}$. When the reaction temperature reached $50^{\circ} \mathrm{C}$, stirring was started $(800 \mathrm{rpm})$ and continued for 0.5 h. After reaction, the reactor was cooled in ice-water (ca. $10^{\circ} \mathrm{C}$ ) to minimize the volatility of the liquid products. The gas phase products were collected using a gas sample bag $(100 \mathrm{~mL})$ and analysed by gas chromatography on an Agilent 7890B gas chromatograph equipped with two columns of Porapak-Q and $5 \mathrm{~A}$ and a thermal conductivity detector (He carrier gas) using $\mathrm{N}_{2}$ as an internal standard. Only $\mathrm{CO}_{2}$ was detected in the gas phase. ${ }^{1} \mathrm{H}-\mathrm{NMR}$ (Bruker, $400 \mathrm{MHz}$ ) spectroscopy was used to determine and quantify liquid phase products. Water suppression was employed to minimise the signal arising from water. Typically, $0.2 \mathrm{~mL} \mathrm{D}_{2} \mathrm{O}, 1.0 \mathrm{~mL}$ sample and DMSO as an internal standard were placed in a NMR tube. ${ }^{1} \mathrm{H}-\mathrm{NMR}$ spectra were recorded with a recycle delay of $5 \mathrm{~s}$ and a spinning rate of 64 scans. The selectivity and productivity of methanol were estimated using the following equations 52,58

Primary oxygenate selectivity $=$ mole of $\left(\mathrm{CH}_{3} \mathrm{OH}+\mathrm{CH}_{3} \mathrm{OOH}\right) /$ total mole of products.

Primary oxygenate productivity $=$ mole of $\left(\mathrm{CH}_{3} \mathrm{OH}+\mathrm{CH}_{3} \mathrm{OOH}\right) /($ weight of metal $(\mathrm{kg}) \times$ reaction time (h))

\subsection{Catalyst characterization}

To determine the morphology and size of the Pd@Pt NPs, transmission electron microscopy (TEM) measurements were performed. For that purpose, the materials were dispersed on a 300-mesh copper TEM grid covered by a carbon film. Low and high resolution transmission electron microscopy (TEM and HREM) observations were carried out with a JEOL JEM-ARM200F Cold FEG (cold field emission gun) equipped with a probe corrector and coupled to an EDX spectrometer and an energy loss spectrometer (EELS). The size distribution was acquired by measuring a minimum of 300 objects and was given as mean standard deviation according to a Gaussian fit of the corresponding size distribution.

CO adsorption-in situ diffuse reflectance infrared Fourier transform spectroscopy (DRIFTS) studies were performed using a Thermo Nicolet iS50-FT-IR spectrometer equipped with a gas-dosing system and a ZnSe window. The IR spectra were recorded at atmospheric pressure with $4 \mathrm{~cm}^{-1}$ in absorbance and a resolution of 64 scans. The colloidal suspensions (containing ca. $5 \mathrm{mg}$ of NPs) were dried in a freeze dryer for $48 \mathrm{~h}$ before their transfer into in situ FT-IR chamber. Nitrogen ( $\mathrm{x}$ ) flux with a flow rate of $50 \mathrm{~mL} / \mathrm{min}$ was applied to clean the catalyst surface before measurement. Then 5 vol.\% $\mathrm{CO} / \mathrm{N}_{2}$ gas was introduced into the FT-IR chamber for $30 \mathrm{~min}$ at r.t. in order to reach a saturated coverage. The $\mathrm{CO}$ adsorption-IR spectra were obtained after the signal for physisorbed $\mathrm{CO}$ species disappeared

The chemical state and the surface composition of the catalysts were analyzed by X-ray photoelectron spectroscopy (XPS) over a XSAM 800 spectrometer (Kratos Co., Ltd.) utilizing Mg K $\alpha$ radiation operating at a power of $150 \mathrm{~W}$. The colloidal samples were previously dried in a freeze dryer for $48 \mathrm{~h}$. XPS analysis was carried out at $13 \mathrm{kV}$ and $20 \mathrm{~mA}$ with a sweep time of $60 \mathrm{~s}$. Pass energies of $160 \mathrm{eV}$ and $40 \mathrm{eV}$ were employed to measure the wide scans and high resolution spectra with a step size of $1.0 \mathrm{eV}$ and $0.1 \mathrm{eV}$, respectively. The signal was corrected using C1s peak level at $284.6 \mathrm{eV}$. The XPS spectra were fitted using a Gaussian-Lorentzian function with a Shirley background on Casa XPS software.

\section{WAXS analysis}

To investigate the average structure of the NPs, Wide-Angle X-ray Scattering (WAXS) studies were performed. ${ }^{59}$ Powder was sealed in a Lindemann glass capillary $1 \mathrm{~mm}$ in diameter. Measurements were carried out using a diffractometer dedicated to the study of amorphous and nanocrystalline samples at the Mo radiation ( $0.71069 \mathrm{~nm}$ ) equipped with a solid state detector in order to achieve low background and effective rejection of $\mathrm{X}$-ray fluorescence radiation. Typical measurements 
covered a range of $129^{\circ}$ in 2 theta with a collection time of $64 \mathrm{~h}$. To access the Radial Distribution Function (RDF), data were reduced then Fourier transformed using classic procedures.

\section{Results and Discussions}

Metal NPs were synthesized by a classical wet chemistry method using $\mathrm{NaBH}_{4}$ as a reductant, PVP as a stabilizer and water as a solvent. The resulting colloidal aqueous suspensions were directly evaluated in methane oxidation using $\mathrm{H}_{2} \mathrm{O}_{2}$ as an oxidant at $3 \mathrm{MPa}$ pressure and $50{ }^{\circ} \mathrm{C}$. Initially, the catalytic activity of monometallic $\mathrm{Pd}$, monometallic $\mathrm{Pt}$, and bimetallic $\mathrm{Pd}_{\mathrm{x}} \mathrm{Pt}_{\mathrm{y}}(\mathrm{x} / \mathrm{y}=1 / 8,1 / 4,1 / 2,1 / 1$, $2 / 1,4 / 1,8 / 1$ ) colloidal catalysts was investigated. A representative NMR spectrum is displayed in Figure 1, where the peaks corresponding to $\mathrm{CH}_{3} \mathrm{OH}(\delta=3.2), \mathrm{CH}_{3} \mathrm{OOH}(\delta=3.7), \mathrm{HCHO}(\delta=4.8), \mathrm{HCOOH}$ $(\delta=8.1)$, and dissolved $\mathrm{CH}_{4}(\delta=0.0)$ were clearly identified. The results of catalytic data are summarized in Table 1. The two metal chloride precursors, their mixture (Table 1, entries 10-12) and PVP alone (Table S1) displayed no catalytic activity for $\mathrm{CH}_{4}$ oxidation, suggesting that the metal NPS were the active species. No carbon-containing products were found in liquid phase or gas phase when $\mathrm{CH}_{4}$ was not charged into the reactor (Table S1), ruling out the possibility of PVP conversion into $\mathrm{C}_{1}$ organic products.

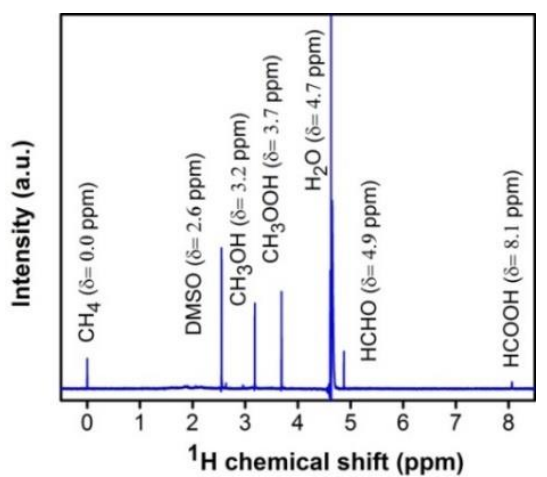

Figure 1. Representative ${ }^{1} \mathrm{H}$-NMR spectrum resulting from $\mathrm{CH}_{4}$ oxidation experiments with identification of the formed products.

As displayed in Table 1, methanol was the only product detected in liquid phase using monometallic Pt NP catalyst (entry 1). A small amount of $\mathrm{CO}_{2}(6 \%)$ was also generated. Despite the high selectivity (94\%), the productivity was relatively low $\left(20 \mathrm{~mol} \mathrm{~kg}_{\text {catalyst }}{ }^{-1} \mathrm{~h}^{-1}\right)$. With monometallic Pd NP catalyst (entry 9), formaldehyde was also formed, leading to a reduced selectivity of methanol (80\%). On the other hand, the productivity of methanol increased to $52 \mathrm{~mol} \mathrm{~kg}$ catalyst $^{-1} \mathrm{~h}^{-1}$, suggesting excellent methane activation ability over Pd NPs. Concerning the series of bimetallic $\mathrm{Pt}_{x} \mathrm{Pd}_{\mathrm{y}} \mathrm{NPs}$, interestingly, reducing the ratio of $\mathrm{Pt}$ to $\mathrm{Pd}$ (entries 5-8) resulted in a decrease in

methanol selectivity but a rise in the productivity. For instance, the bimetallic $\mathrm{Pt}_{1} \mathrm{Pd}_{1} \mathrm{NP}$ catalyst exhibited high selectivity (86\%) and yield $\left(62.7 \mathrm{~mol} \mathrm{~kg}\right.$ catalyst $\left.^{-1} \mathrm{~h}^{-1}\right)$, exhibiting superior productivity towards $C_{1}$ primary oxygenate to that obtained over monometallic Pt NPs and Pd NPs. To identify the most suitable configuration of Pd and Pt in the PdPt bimetallic NPs for methane oxidation, Pt@Pd and Pd@Pt NPs were prepared following a seeded growth method and further tested (entries 1314). Pd@Pt NPs, prepared by consecutive reduction of Pd and Pt precursors, provided the highest selectivity $(92 \%)$ and productivity $\left(89.3 \mathrm{~mol} \mathrm{~kg}_{\text {catalyst }}{ }^{-1} \mathrm{~h}^{-1}\right)$ toward methanol.
TEM analysis revealed the presence of isolated Pd@Pt NPs together with aggregates of 10-50 nm in size (Figure S2). An average size of $3.4 \pm 2.2 \mathrm{~nm}$ was determined for the Pd@Pt NPs. STEM-EDX analysis on the NP aggregates indicated close mass contents of Pd and Pt (ca. 54 and $46 \%$, respectively; Figure S3). Few isolated pure Pt NPs (Figure S4) were also observed. Given their mean size, the calculated turnover frequency (TOF) per surface metal site of Pd@Pt NPs was found to be XXX (Figure S1, Table S2). This result is much higher than those of Pd, Pt or PdPt samples, indicating a different intrinsic activity. The performance obtained with Pd@Pt catalyst is comparable or even better than that of recent published systems like Au-Pd colloids, ${ }^{51} \mathrm{AuPd} / \mathrm{ZSM}-5-\mathrm{R},{ }^{58} \mathrm{PdxCu1-xO} / \mathrm{C}^{60}$ and $\mathrm{Rh} / \mathrm{TiO}_{2}{ }^{42}$ (Table S3).
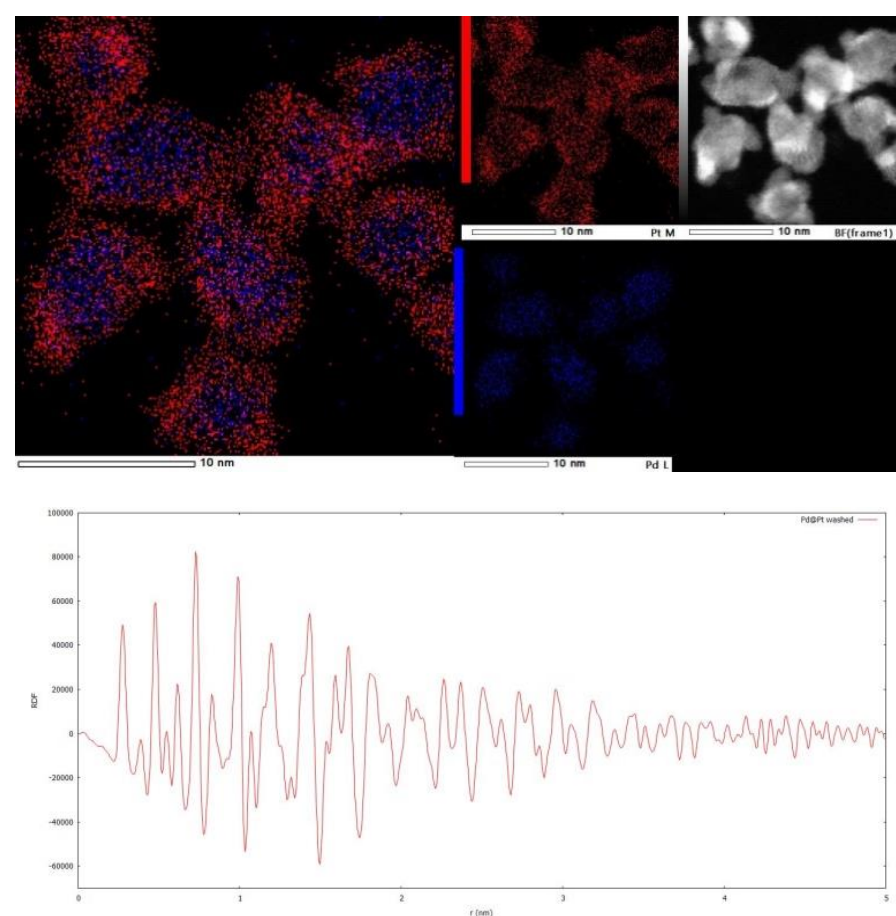

Figure 2. Top: STEM-EDX elemental mapping of Pd@Pt NPs where Platinum appears in red and Palladium in blue. Bottom: Radial distribution function (RDF) of the Pd@Pt NP sample.

Figure 2 presents the STEM-EDX analysis of the Pd@Pt NPs. The elemental mapping clearly evidenced a predominant enrichment of Pd in the NP core while the surface layer is more Pt-riched, thus indicating NPs with a Pd-core-Pt-shell structure. Fourier transform of a STEM-HREM dark field image of Pd@Pt particles showed only one diffraction pattern attributable to Pt. This result indicates a potential epitaxial growth of Pt over Pd cores (Figure S5). The analysis above suggest the sample comprise both core-shell Pd@Pt NPs and pure Pt NPs. Compared with activity data of Pt NPs (entry 1, Table 1), the Pd@Pt sample (entry 14) showed significantly enhanced productivity to oxygenates, supporting the dominant role of the core-shell structure in providing superior activity.

In order to complete the structural analysis of the Pd@Pt NPs, WAXS analysis was applied. As showed in Figure S6, the diffractogram obtained corresponds well to the fcc structure, just like Pd and Pt, however a much better agreement with pure Pd can be observed. The related crystallographic parameter was estimated to be $0.3898 \mathrm{~nm}$, intermediate between values for pure $\mathrm{Pd}(0.3890 \mathrm{~nm})$ and pure Pt $(0.3923 \mathrm{~nm})$. For bimetallic NPs, deviation to Vegard's law was previously observed and interpreted as a core-shell organization rather than alloying. ${ }^{59}$ In the present case, the minimal deviation to Pd parameter points to segregation with Pd at the core and Pt at the shell. Regarding 
Pt, structural order is more ambiguous since as a rule the thin less ordered shell marginally contributes to the scattering and WAXS alone cannot distinguish between a disordered shell and a well ordered one in epitaxial growth over a Pd core. In real space (Figure 2), the lack of short C-C

Table 1. Catalytic performance of the NP samples and metal precursors tested for direct methane oxidation. ${ }^{\mathrm{a}}$

\begin{tabular}{|c|c|c|c|c|c|c|c|c|}
\hline \multirow[t]{2}{*}{ Entry } & \multirow[t]{2}{*}{ Catalysts: $\mathrm{Pt}_{\mathrm{x}} \mathrm{Pd}_{\mathrm{y}}$} & \multicolumn{5}{|c|}{ Concentration of Product ( $\left.\mathrm{mol} / \mathrm{mol}_{\text {metal }}\right)$} & \multirow{2}{*}{$\begin{array}{l}\text { Primary } \\
\text { oxygenate } \\
\text { selectivity (\%) }\end{array}$} & \multirow{2}{*}{$\begin{array}{l}\text { Primary oxygenate } \\
\text { productivity (mol } \\
\mathrm{kg}_{\text {catalyst }}{ }^{-1} \mathrm{~h}^{-1} \text { ) }\end{array}$} \\
\hline & & $\mathrm{CH}_{3} \mathrm{OH}$ & $\mathrm{CH}_{3} \mathrm{OOH}$ & $\mathrm{HCHO}$ & $\mathrm{HCOOH}$ & $\mathrm{CO}_{2}$ & & \\
\hline 1 & $x / y=10 / 0$ & 1.5 & 0 & 0 & 0 & 0.1 & 94 & 20.0 \\
\hline 2 & $x / y=8 / 1$ & 2.0 & 0 & 0 & 0 & 0.1 & 95 & 26.7 \\
\hline 3 & $x / y=4 / 1$ & 2.7 & 0 & 0 & 0 & 0.2 & 93 & 36.0 \\
\hline 4 & $x / y=2 / 1$ & 3.2 & 0 & 0 & 0 & 0.3 & 91 & 42.7 \\
\hline 5 & $x / y=1 / 1$ & 3.5 & 1.2 & 0.4 & 0 & 0.4 & 86 & 62.7 \\
\hline 6 & $x / y=1 / 2$ & 3.7 & 2.6 & 0.9 & 0.7 & 0.4 & 76 & 84.0 \\
\hline 7 & $x / y=1 / 4$ & 2.8 & 3.7 & 4.4 & 3.1 & 0.4 & 45 & 88.0 \\
\hline 8 & $x / y=1 / 8$ & 3.0 & 3.6 & 1.6 & 0.4 & 0.5 & 72 & 88.0 \\
\hline 9 & $x / y=0 / 10$ & 2.4 & 1.5 & 0.6 & 0 & 0.4 & 80 & 52.0 \\
\hline 10 & $\mathrm{~K}_{2} \mathrm{PtCl}_{4}$ & 0 & 0 & 0 & 0 & 0.3 & 0 & 0 \\
\hline 11 & $\mathrm{H}_{2} \mathrm{PdCl}_{4}$ & 0 & 0 & 0 & 0 & 0.5 & 0 & 0 \\
\hline 12 & $\mathrm{~K}_{2} \mathrm{PtCl}_{4}+\mathrm{H}_{2} \mathrm{PdCl}_{4}$ & 0 & 0 & 0 & 0 & 0.4 & 0 & 0 \\
\hline 13 & Pt@Pd & 2.8 & 3.4 & 0.8 & 1.0 & 0.5 & 73 & 82.6 \\
\hline 14 & $P d @ P t$ & 2.3 & 4.4 & 0.3 & 0 & 0.3 & 92 & 89.3 \\
\hline
\end{tabular}

a Catalysis conditions: $1 \mu \mathrm{mol}$ metal in $2 \mathrm{~mL}$ deionized water; 30 bar $\mathrm{CH}_{4}, 0.4 \mathrm{~mL}$ of $1 \mathrm{M} \mathrm{H}_{2} \mathrm{O}_{2}, 50{ }^{\circ} \mathrm{C}$ for $0.5 \mathrm{~h}, 800 \mathrm{rpm}$. distance confirms that PVP contribution to scattering can be neglected. On the basis of coherence ength, the average size for crystallites is in the range 3.6-3.9 nm. 
XPS analysis was performed on Pd@Pt anocatalyst (Figure S7). 59 \% of surface Pt is $\mathrm{Pt}^{0}\left(\mathrm{Pt}_{4 \mathrm{f}} \sim 70.8\right.$ $\mathrm{eV})^{61}$ and $39 \%$ of surface $\mathrm{Pd}$ is $\mathrm{Pd}^{0}\left(\mathrm{Pd}_{3 \mathrm{~d}} \sim 335.0 \mathrm{eV}\right), 62,63$ likely due to oxidation of both elements after synthesis. CO adsorption experiments were carried out on Pd, Pt and Pd@Pt catalysts using DRIFTS technique (Figure 3). The IR bands observed at 1972 and $1913 \mathrm{~cm}^{-1}$ for Pd-PVP NPs can be assigned to the bridging $\mathrm{CO}$ adsorption on the step sites of $\mathrm{Pd} \mathrm{NPs} \mathrm{or} \mathrm{on} \mathrm{Pd}(100) / \mathrm{Pd}(111)$ facets. ${ }^{64-}$ ${ }^{66}$ The predominant $2130 \mathrm{~cm}^{-1}$ IR peak corresponds to linear $\mathrm{Pd}^{2+-} \mathrm{CO}$ bond, $62,67,68$ thus suggesting partial oxidation of metallic Pd during the sample preparation, which is consistent with the XPS results. For Pt NPs, only one CO absorption band is visible at $2056 \mathrm{~cm}^{-1}$, which is ascribed to linear adsorbed CO on unsaturated Pt sites.69,70 A similar phenomenon was observed with Pd@Pt NPs, thus confirming that Pt is located at the NP surface. However, on Pd@Pt NPs the CO absorption band appears at a lower wavenumber than that observed on Pt NPs $\left(2051 \mathrm{~cm}^{-1}\right.$ against $\left.2056 \mathrm{~cm}^{-1}\right)$. This shift towards lower frequencies is ascribed to an electron transfer from Pd to Pt due to their electronegativity difference.

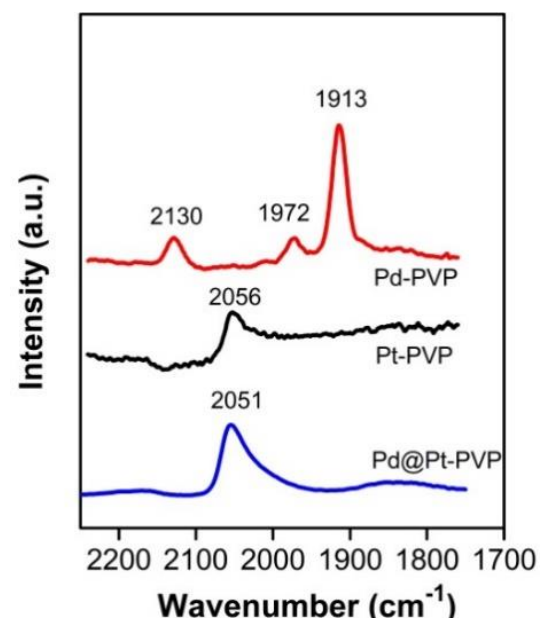

Figure 3. In situ DRIFTS of CO chemisorption on Pd, Pt and Pd@Pt NP samples at r.t.

The Pd@Pt NP catalyst was further investigated. Figure 4a shows its catalytic performances obtained at 25,50 , and $70{ }^{\circ} \mathrm{C}$, respectively. Pd@Pt NPs provided a much lower productivity (oxygenate product: $2.2 \mu \mathrm{mol}$ ) despite a high methanol selectivity $(89 \%)$ at $25^{\circ} \mathrm{C}$. Increasing the temperature to $70{ }^{\circ} \mathrm{C}$ significantly enhanced the yield (oxygenate products: $8.2 \mu \mathrm{mol}$ ) but slightly decreased methanol selectivity (87\%) due to the favorable formation of $\mathrm{CO}_{2}$ as a by-product. Interestingly, the reaction performed at $50{ }^{\circ} \mathrm{C}$ evidenced considerably improved catalytic activity (oxygenate products: $7.0 \mu \mathrm{mol}$ ) and selectivity (92.4\%). From the slope of Arrhenius plot, the apparent activation energy is estimated to be $45 \mathrm{~kJ} / \mathrm{mol}$, a value that is comparable to those previously reported with highly

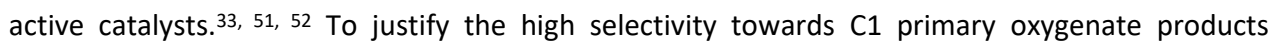
observed with the Pd@Pt colloidal catalyst, methanol was used as the reactant instead of methane (Figure 4b). Only a low conversion (ca. 10\%) of methanol into formaldehyde was observed under these conditions, suggesting that Pd@Pt NPs are not active for the oxidation of methanol, thus minimize undesired over-oxidation. (a)

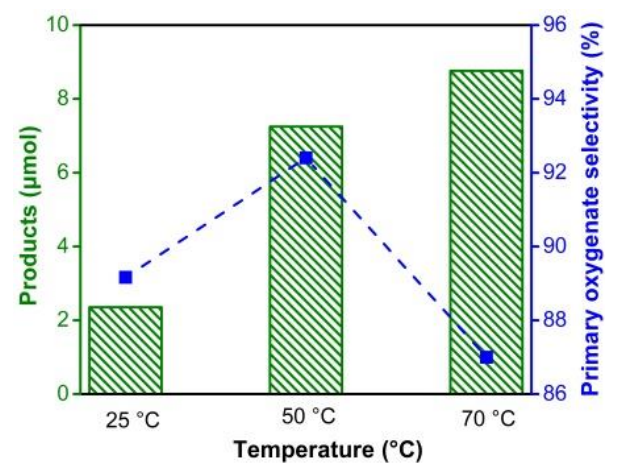

(b)

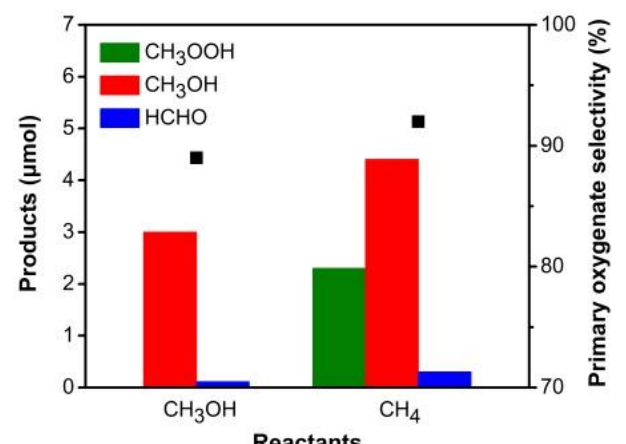

Figure 4. (a) Activity and selectivity obtained in methane oxidation at 25,50 , and $70{ }^{\circ} \mathrm{C}$ with 400 $\mu$ mol of $\mathrm{H}_{2} \mathrm{O}_{2}$ and 30 bar of $\mathrm{CH}_{4}$ over Pd@Pt NPs; (b) Catalytic performance using $\mathrm{CH}_{3} \mathrm{OH}$ (3.2 $\mu$ mol) and $\mathrm{CH}_{4}$ (30 bar) as reactants over Pd@Pt NPs.

Kinetic analysis was performed by changing the $\mathrm{H}_{2} \mathrm{O}_{2}$ concentration and $\mathrm{CH}_{4}$ pressure. As shown in Figure $5 \mathrm{a}-\mathrm{c}$, the reaction is first order with regard to both $\mathrm{H}_{2} \mathrm{O}_{2}$ and $\mathrm{CH}_{4}$ under the tested conditions $\left(\left[\mathrm{H}_{2} \mathrm{O}_{2}\right]=100-400 \mu \mathrm{mol}, \mathrm{P}\left(\mathrm{CH}_{4}\right)=10-30 \mathrm{bar}\right)$. The rate-determining step, therefore, involves both activation of $\mathrm{H}_{2} \mathrm{O}_{2}$ and $\mathrm{CH}_{4}$. On the basis of $\mathrm{H}_{2} \mathrm{O}_{2}$ consumption, the initial rate was employed to calculate the pseudo first-order rate constant at the applied temperature.

Figure $5 \mathrm{~d}$ presents the variation of catalytic performance of $\mathrm{CH}_{4}$ oxidation as a function of $\mathrm{H}_{2} \mathrm{O}_{2}$ concentration. The Pd@Pt NP catalyst showed a volcano-shaped dependence of the oxygenated products on the amount of $\mathrm{H}_{2} \mathrm{O}_{2}$ added. A similar trend was also observed on the selectivity of methanol. Increasing $\mathrm{H}_{2} \mathrm{O}_{2}$ amount from 400 to $4000 \mu \mathrm{mol}$ led to a remarkable, monotonous decrease both in oxygenated products (from 7 to $1.2 \mu \mathrm{mol}$ ) and in methanol selectivity (from $92 \%$ to $42 \%$ ). According to the literature, ${ }^{16,48} \mathrm{H}_{2} \mathrm{O}_{2}$ undergoes splitting supplying $\cdot \mathrm{OH}$ radicals, and the activation of $\mathrm{CH}_{4}$ occurred via a radical mechanism. It was reported that excessive $\mathrm{H}_{2} \mathrm{O}_{2}$ leads to termination of the reaction and thus reduces the product formation. ${ }^{52}$ Note that the Pd@Pt NP catalyst precipitated to some extent in the presence of a large amount of $\mathrm{H}_{2} \mathrm{O}_{2}(4000 \mu \mathrm{mol})$ (Figure S8). Decreasing $\mathrm{H}_{2} \mathrm{O}_{2}$ concentration from 400 to $100 \mu \mathrm{mol}$ led to a decline both in $\mathrm{C} 1$ liquid products (from 7 to $2.4 \mu \mathrm{mol}$ ) and in methanol selectivity (from $92 \%$ to $84 \%$ ). This may be due to limited amount of available radicals in the reaction mixture. There is thus an optimum $\mathrm{H}_{2} \mathrm{O}_{2}$ concentration to achieve the highest methanol selectivity and yield. 

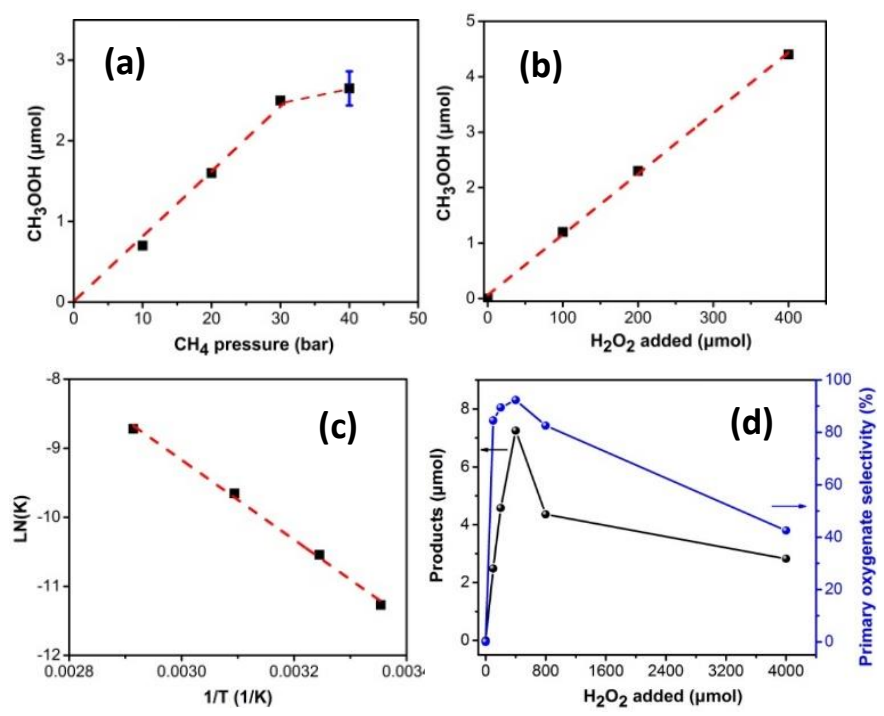

Figure 5. Dependence of the amount of formed $\mathrm{CH}_{3} \mathrm{OOH}$ on (a) $\mathrm{CH}_{4}$ pressure and (b) concentration of $\mathrm{H}_{2} \mathrm{O}_{2}$ added; (c) the Arrhenious plot for methane oxidation reaction; (d) Effects of $\mathrm{H}_{2} \mathrm{O}_{2}$ concentration on productivity and selectivity over Pd@Pt NPs at $50{ }^{\circ} \mathrm{C}$ for $0.5 \mathrm{~h}$.

The reaction pathway was studied by analyzing the evolution of products as a function of time (up to $170 \mathrm{~min}$, Figure 6). The amount of $\mathrm{CH}_{3} \mathrm{OOH}$ increased progressively in the first 80 min and decreased afterwards. However, the quantity of $\mathrm{CH}_{3} \mathrm{OH}, \mathrm{HCHO}, \mathrm{HCOOH}$, and $\mathrm{CO}_{2}$ continued to increase with the reaction time. In addition, $\mathrm{CH}_{3} \mathrm{OOH}$ and $\mathrm{CH}_{3} \mathrm{OH}$ appeared in product stream from the beginning, while $\mathrm{HCHO}$ and $\mathrm{CO}_{2}$ were only observed after $30 \mathrm{~min}$. The total yield of products firstly upsurged and then, decreased from $80 \mathrm{~min}$ onwards. This is in agreement with the consumption rate of $\mathrm{H}_{2} \mathrm{O}_{2}$ in the reaction medium (Table S4). Extra $\mathrm{H}_{2} \mathrm{O}_{2}$ was added in the reaction mixture after $80 \mathrm{~min}$. A similar oxidation rate was attained and thus more oxygenate products were formed. Besides, no obvious precipitation for Pd@Pt NP catalyst was observed at the end of the reaction.

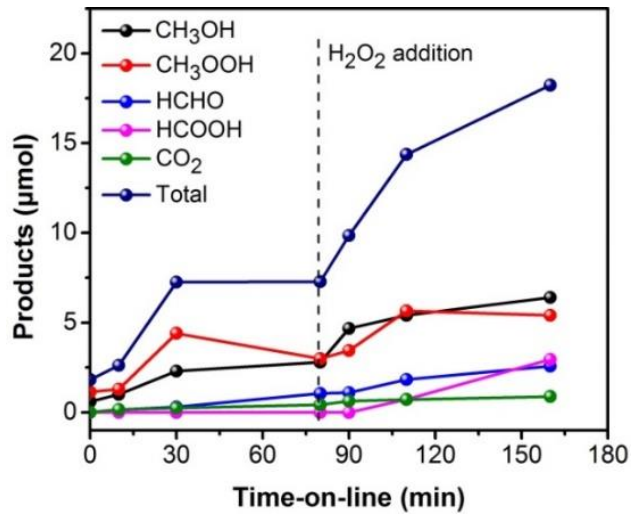

Figure 6. Catalytic performance of $\mathrm{CH}_{4}$ oxidation over Pd@Pt NPs with varied reaction times and reuse-ability investigation.

These results indicate that $\mathrm{CH}_{4}$ was first converted into $\mathrm{CH}_{3} \mathrm{OOH}$, which may be formed via the reaction between $\cdot \mathrm{CH}_{3}$ and $\cdot \mathrm{OOH}$, or between $\mathrm{CH}_{3} \mathrm{OO} \cdot$ and $\cdot \mathrm{H} \cdot{ }^{33,}, 52$ It was previously well established that $\mathrm{CH}_{3} \mathrm{OOH}$ can be easily deoxidized to $\mathrm{CH}_{3} \mathrm{OH}{ }^{16}, 40,52$. Further oxidation of $\mathrm{CH}_{3} \mathrm{OH}$ can lead to $\mathrm{HCHO}, \mathrm{HCOOH}$, and $\mathrm{CO}_{2} .47,48 \mathrm{Here}$, when $\mathrm{CH}_{3} \mathrm{OH}$ was directly used as the reactant instead of $\mathrm{CH}_{4}$
(Figure 4b), formation of a small amount of $\mathrm{HCHO}$ and $\mathrm{CO}_{2}$ was confirmed by ${ }^{1} \mathrm{H}$ NMR and GC-TCD analysis, respectively. Combined, $\mathrm{CH}_{3} \mathrm{OOH}$ is a key intermediate in the reaction, which formed via $\mathrm{CH}_{4}$ oxidation and is then converted into $\mathrm{CH}_{3} \mathrm{OH}, \mathrm{HCHO}, \mathrm{HCOOH}$, and $\mathrm{CO}_{2} \cdot{ }^{35,40,47,48,52}$

A three step reaction mechanism is proposed in Scheme 1. In step 1, the decomposition of $\mathrm{H}_{2} \mathrm{O}_{2}$ catalyzed by Pd@Pt produces $\mathrm{H}_{2} \mathrm{O}$ and $\mathrm{O}_{2}$ as well as three radicals $\cdot \mathrm{H}, \cdot \mathrm{OOH}$, and $\cdot \mathrm{OH}$. Compared with $\cdot \mathrm{H}$ and $\cdot \mathrm{OOH} \cdot \mathrm{OH}$ radical species is known to be highly effective for methane activation via subtraction of a $\mathrm{H}$ atom to produce $\cdot \mathrm{CH}_{3}$ radicals (step (2)). ${ }^{16,22,36} \mathrm{~A}$ Fe-based Fenton's type catalyst, well-known for its ability to generate $\cdot \mathrm{OH}$ radicals, ${ }^{71,} 72$ was also investigated (Table S5). A significantly lower amount of products was detected over this Fe-based Fenton's type catalyst compared with Pd@Pt NPs, demonstrating that Pd@Pt nanocatalyst also played an active role in methane activation in step (2). Considering the first order kinetic behavior, we propose both $\mathrm{H}_{2} \mathrm{O}_{2}$ and methane are adsorbed on the surface of NPs with comparable coverage. $\mathrm{H}_{2} \mathrm{O}_{2}$ dissociates to provide $\cdot \mathrm{OH}$ radicals at the surface of Pd@Pt NPs, which then activates adsorbed $\mathrm{CH}_{4}$ by forming $\cdot \mathrm{CH}_{3}$ radicals. In the solution, $\cdot \mathrm{OH}$ is able to oxidize $\mathrm{H}_{2} \mathrm{O}_{2}$ to form more stable $\cdot \mathrm{OOH}$ species ${ }^{73}$, so that in the liquid phase $\cdot \mathrm{OOH}$ would be dominant. As such, selective oxidation of methane mainly occurs on the catalyst surface rather than in the solution. As we are aware, the active role of surface reactions on NPs in $\mathrm{H}_{2} \mathrm{O}_{2}$ oxidized methane conversion to methanol has not been explicitly mentioned in previous studies.

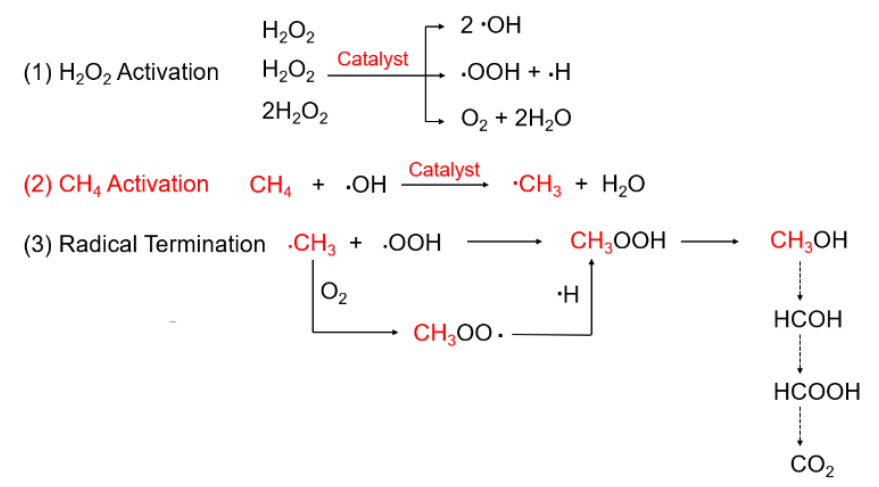

Scheme 1. Schematic representation of proposed radical mechanism.

\section{Conclusions}

In this work, core-shell Pd@Pt NPs proved to be a performant catalyst for methanol synthesis via the direct oxidation of methane in water using $\mathrm{H}_{2} \mathrm{O}_{2}$ as an oxidant and mild reaction conditions. This catalyst led to a high selectivity (92.4\%) and productivity ( $89.3 \mathrm{mmol}$ g metal-1 $\mathrm{h}-1$ ) and was found stable with time-on-line testing at $50{ }^{\circ} \mathrm{C}$ and $400 \mu \mathrm{mol} \mathrm{H}_{2} \mathrm{O}_{2}$. A consecutive oxidation pathway via radical mechanism was identified: methane was firstly converted to methyl hydroperoxide and methanol, and methanol was then oxidized to formaldehyde, formic acid, and carbon dioxide. As evidenced from the control experiments and kinetic analysis, Pd@Pt NPs were crucial for the activation of methane, and played a positive role in both $\mathrm{H}_{2} \mathrm{O}_{2}$ splitting and $\mathrm{C}-\mathrm{H}$ bond activation. In situ CO-DRIFTS results indicated a high surface electron density around Pt due to Pd electron donation, and this electronic interaction between $\mathrm{Pt}$ and $\mathrm{Pd}$ may be the origin for enhanced catalytic performance. 


\section{Conflicts of interest}

There are no conflicts to declare.

\section{Acknowledgements}

The french National Agency for Research (project $n^{\circ}$ ANR-17-CE06-0017-01) and the Singapore National Research Foundation (WBS: R-279-000-530-281) are gratefully acknowledged for the financial support. The authors also thank UMS R. Castaing microcaracterization center for the access to electron microscopy equipments.

\section{References}

R. A. Kerr, Science, 2010, 328, 1624.

B. Liu, L. Tian, L. Li, C. Au and A. C. Cheung, AlChE J., 2011, 57, 1852-1859.

C. D. Elvidge, M. Zhizhin, K. Baugh, F.-C. Hsu and T. Ghosh, Energies, 2016, 9, 14.

E. McFarland, Science, 2012, 338, 340-342.

M. Kumar, G. Rattan and R. Prasad, Can. Chem. Trans., 2015, 3, 381-409.

P. Tang, Q. Zhu, Z. Wu and D. Ma, Energy Environ. Sci., 2014, 7, 2580-2591.

T. V. Choudhary and V. R. Choudhary, Angew. Chem. Int. Ed., 2008, 47, 1828-1847.

J. R. Rostrup-Nielsen, J. Sehested and J. K. Nørskov, Adv. Catal., 2002, 47, 65-139.

S. Bharadwaj and L. Schmidt, Fuel Process. Technol., 1995, 42, 109-127.

M. E. Dry, Catal. Today, 2002, 71, 227-241.

J. R. Rostrup-Nielsen, Catal. Today, 1993, 18, 305-324.

I. Dybkjær and K. Aasberg - Petersen, Can. J. Chem. Eng., 2016, 94, 607-612.

A. Caballero and P. J. Pérez, Chem. Soc. Rev., 2013, 42, 8809-8820.

E. Fiedler, G. Grossmann, D. B. Kersebohm, G. Weiss and C. Witte, Ullmann's encyclopedia of industrial chemistry, 2000.

M. Behrens, F. Studt, I. Kasatkin, S. Kühl, M. Hävecker, F. Abild-Pedersen, S. Zander, F. Girgsdies, P. Kurr and B.-L. Kniep, Science, 2012, 336, 893-897.

A. I. Olivos-Suarez, À. Szécsényi, E. J. M. Hensen, J. Ruiz-Martinez, E. A. Pidko and J. Gascon, ACS Catal., 2016, 6, 2965-2981.

. Arndtsen, R. G. Bergman, T. A. Mobley and T. H. Peterson, Acc. Chem. Res., 1995, 28, 154-162.

18. A. Holmen, Catal. Today, 2009, 142, 2-8

19. X. Guo, G. Fang, G. Li, H. Ma, H. Fan, L. Yu, C. Ma, X. Wu, D. Deng, M. Wei, D. Tan, R. Si, S. Zhang J. Li, L. Sun, Z Tang X. Pan and X. Bao, Science, 2014, 344, 616-619.

R. Horn and R. Schlögl, Catal. Lett., 2015, 145, 23-39.

A. Galadima and O. Muraza, J. Ind. Eng. Chem., 2016, 37, 1-13.

P. Schwach, X. Pan and X. Bao, Chem. Rev., 2017, 117, 8497-8520.

Y. Dou, Y. Pang, L. Gu, Y. Ding, W. Jiang, X. Feng, W. Ji and C.-T. Au, J. Energy Chem., 2018, 27, 883-889.

C.-G. Zhan, J. A. Nichols and D. A. Dixon, J. Phys. Chem. A, 2003, 107, 4184-4195.

M. C. Paganini, M. Chiesa, P. Martino, E. Giamello and E. Garrone, J. Phys. Chem. B, 2003, 107, 2575-2580 A. Perian

M. O. Adebajo, Green Chem, $2007,9,526-539$.

M. Ahlquist, R. J. Nielsen, R. A. Periana and W. A. Goddard III, J. Am. Chem. Soc., 2009, 131, $17110-17115$

K. Otsuka and Y. Wang, Appl. Catal., A., 2001, 222, 145-161.

30. A. A. Latimer, A. Kakekhani, A. R. Kulkarni and J. K. Nørskov, ACS Catal., 2018, 8, 68946907.

31. E. G. Chepaikin, G. N. Boyko, A. P. Bezruchenko, A. A. Leshcheva and E. H. Grigoryan, Mol. Catal. A: Chem., 1998, 129, 15-18.

32. R. A. Periana, D. J. Taube, E. R. Evitt, D. G. Löffler, P. R. Wentrcek, G. Voss and T. Masuda, Science, 1993, 259, 340-343.
C. Hammond, M. M. Forde, M. H. Ab Rahim, A. Thetford, Q. He, R. L. Jenkins, N. Dimitratos, J. A. Lopez-Sanchez, N. F. Dummer, D. M. Murphy, A. F. Carley, S. H. Taylor, D. J. Willock E. E. Stangland, J. Kang, H. Hagen, C. J. Kiely and G. J. Hutchings, Angew. Chem. Int. Ed. Engl., 2012, 51, 5129-5133.

M. H. Ab Rahim, M. M. Forde, R. L. Jenkins, C. Hammond, Q. He, N. Dimitratos, J. A. LopezSanchez, A. F. Carley, S. H. Taylor, D. J. Willock, D. M. Murphy, C. J. Kiely and G. J. Hutchings, Angew. Chem. Int. Ed. Engl., 2013, 52, 1280-1284.

S. Al-Shihri, C. J. Richard and D. Chadwick, Chem CatChem, 2017, 9, 1276-1283.

P. Tomkins, M. Ranocchiari and J. A. van Bokhoven, Acc. Chem. Res., 2017, 50, 418-425.

M. H. Mahyuddin, A. Staykov, Y. Shiota and K. Yoshizawa, ACS Catal., 2016, 6, 8321-8331. M. Ravi, M. Ranocchiari and J. A. van Bokhoven, Angew. Chem. Int. Ed. Engl., 2017, 56, 16464-16483.

39. D. P. Vitaly L. Sushkevich, Marco Ranocchiari, Jeroen A. van Bokhoven, Science, 2017, 356, 523-527.

40. X. Meng, X. Cui, N. P. Rajan, L. Yu, D. Deng and X. Bao, Chem, 2019, 5, 2296-2325.

41. Y. Kwon, T. Y. Kim, G. Kwon, J. Yi and H. Lee, J. Am. Chem. Soc., 2017, 139, 17694-17699.

42. J. Shan, M. Li, L. F. Allard, S. Lee and M. Flytzani-Stephanopoulos, Nature, 2017, 551, 605608.

43. S. Bai, F. Liu, B. Huang, F. Li, H. Lin, T. Wu, M. Sun, J. Wu, Q. Shao, Y. Xu and X. Huang, Nat Comm., 2020, 11, 954.

44. Y. L. Yu Tang, Victor Fung, De-en Jiang, Weixin Huang, Shiran Zhang, Yasuhiro Iwasawa, and L. N. Tomohiro Sakata, Xiaoyan Zhang, Anatoly I. Frenkel \& Franklin (Feng) Tao, Nat. Comm., 2018, 9, 1231

45. A. Wang, J. Li and T. Zhang, Nat. Rev. Chem., 2018, 2, 65-81.

46. W. Huang, S. Zhang, Y. Tang, Y. Li, L. Nguyen, Y. Li, J. Shan, D. Xiao, R. Gagne, A. I. Frenkel and F. Tao, Angew. Chem. Int. Ed., 2016, 55, 13441-13445.

47. X. Cui, H. Li, Y. Wang, Y. Hu, L. Hua, H. Li, X. Han, Q. Liu, F. Yang, L. He, X. Chen, Q. Li, J. Xiao, D. Deng and X. Bao, Chem, 2018, 4, 1902-1910.

Q. Shen, C. Cao, R. Huang, L. Zhu, X. Zhou, Q. Zhang, L. Gu and W. Song, Angew. Chem. Int Ed., 2020, 132, 1232-1235.

R. J. Lewis, A. Bara-Estaun, N. Agarwal, S. J. Freakley, D. J. Morgan and G. J. Hutchings, Catal. Lett., 2019, 149, 3066-3075.

Y. He, C. Luan, Y. Fang, X. Feng, X. Peng, G. Yang and N. Tsubaki, Catal. Today, 2020, 339, 48-53.

R. McVicker, N. Agarwal, S. J. Freakley, Q. He, S. Althahban, S. H. Taylor, C. J. Kiely and G. J. Hutchings, Catal. Today, 2020, 342, 32-38.

S. J. F. Nishtha Agarwal, Rebecca U. McVicker, Sultan M. Althahban,, Q. H. Nikolaos Dimitratos, David J. Morgan, Robert L. Jenkins, and S. H. T. David J. Willock, Christopher J. Kiely, Graham J. Hutchings, Science, 2017, 358, 223-227.

J. Zhu, L. Wang, E. Zuidema, K. Mondal, M. Zhang, J. Zhang, C. Wang, X. Meng, H. Yang, C. Mesters and F. Xiao, Science, 2020, 367, 193-197.

Q. Zhao, B. Liu, Y. Xu, F. Jiang and X. Liu, New J. Chem., 2020.

Q. Achatz, C. Berg, S. Joos, B. S. Fox, M. K. Beyer, G. Niedner-Schatteburg and V. E. Bondybey, Chem. Phys. Lett., 2000, 320, 53-58.

G. Psofogiannakis, A. St-Amant and M. Ternan, J. Phys. Chem. B, 2006, 110, 24593-24605. L. Xiao and L. Wang, J. Phys. Chem. B, 2007, 111, 1657-1663.

Z. Jin, L. Wang, E. Zuidema, K. Mondal, M. Zhang, J. Zhang, C. Wang, X. Meng, H. Yang, C. Mesters and F.-S. Xiao, Science, 2020, 367, 193

C. Bergounhou, C. Blandy, R. Choukroun, P. Lecante, C. Lorber and J.-L. Pellegatta, New J. Chem, 2007, 31, 218-223.

60. S. Bai, Y. Xu, P. Wang, Q. Shao and X. Huang, ACS Catal., 2019, 9, 6938-6944.

61. J. Chen, Y. Wu, W. Hu, P. Qu, X. Liu, R. Yuan, L. Zhong and Y. Chen, Mol. Catal., 2020, 496, 111185.

62. J. Chen, J. Zhong, Y. Wu, W. Hu, P. Qu, X. Xiao, G. Zhang, X. Liu, Y. Jiao, L. Zhong and Y. Chen, ACS Catal., 2020, 10, 10339-10349.

J. Chen, Y. Wu, W. Hu, P. Qu, G. Zhang, P. Granger, L. Zhong and Y. Chen, Appl. Catal. B, 2020, 264, 118475.

64. J. H. Carter, S. Althahban, E. Nowicka, S. J. Freakley, D. J. Morgan, P. M. Shah, S. Golunski, C. J. Kiely and G. J. Hutchings, ACS Catal., 2016, 6, 6623-6633.

L. Ding, H. Yi, W. Zhang, R. You, T. Cao, J. Yang, J. Lu and W. Huang, ACS Catal., 2016, 6, 3700-3707. 
66. K. Murata, Y. Mahara, J. Ohyama, Y. Yamamoto, S. Arai and A. Satsuma, Angew. Chem. Int. Edit., 2017, 129, 1-6.

67. Y. Lou, J. Ma, W. Hu, Q. Dai, L. Wang, W. Zhan, Y. Guo, X.-M. Cao, Y. Guo, P. Hu and G. Lu, ACS Catal., 2016, 6, 8127-8139.

68. S. Royer and D. Duprez, ChemCatChem, 2011, 3, 24-65.

69. Q. Sun, N. Wang, Q. Fan, L. Zeng, A. Mayoral, S. Miao, R. Yang, Z. Jiang, W. Zhou, J. Zhang, T. Zhang, J. Xu, P. Zhang, J. Cheng, D.-C. Yang, R. Jia, L. Li, Q. Zhang, Y. Wang, O. Terasaki and J. Yu, Angew. Chem. Int. Ed., 2020.

70. J. Zhu, T. Wang, X. Xu, P. Xiao and J. Li, Appl. Catal. B, 2013, 130-131, 197-217.

71. F. Haber, J. Weiss and W. J. Pope, Proc. Math. Phys. Eng. Sci., 1934, 147, 332-351.

72. A. Babuponnusami and K. Muthukumar, J. Environ. Chem. Eng., 2014, 2, 557-572.

73. R. J. Buszek, M. Torrent-Sucarrat, J. M. Anglada and J. S. Francisco, J. Phys. Chem. A, 2012, 116, 5821-5829. 